\title{
Management of gastrointestinal stromal tumors: A 10-year experience of a single surgical department
}

\author{
Dariusz Janczak ${ }^{1,2, A, F}$, Jacek Rać ${ }^{1, B, D}$, Wiktor Pawłowski, ${ }^{1,2, A, D}$, Tadeusz Dorobisz ${ }^{1,3, C, E}$, \\ Agnieszka Ziomek ${ }^{1,2, B}$, Dawid Janczak ${ }^{3, C, D}$, Michał Leśniak ${ }^{1,2, C, E}$, Mariusz Chabowski ${ }^{1,2, D, F}$ \\ ${ }^{1}$ Department of Surgery, $4^{\text {th }}$ Military Teaching Hospital, Wrocław, Poland \\ 2 Division of Surgical Procedures, Department of Clinical Nursing, Faculty of Health Sciences, Wroclaw Medical University, Poland \\ ${ }^{3}$ Division of Oncology and Palliative Care, Faculty of Health Sciences, Wroclaw Medical University, Poland \\ A - research concept and design; B - collection and/or assembly of data; C - data analysis and interpretation; \\ $D$ - writing the article; $E$ - critical revision of the article; $F$ - final approval of the article
}

\section{Address for correspondence \\ Mariusz Chabowski}

E-mail:mariusz.chabowski@gmail.com

Funding sources

None declared

\section{Conflict of interest}

None declared

Received on July 28, 2016

Reviewed on 0ctober 8, 2016

Accepted on January 29, 2017

DOI

10.17219/acem/68718

\section{Copyright}

Copyright by Author(s)

This is an article distributed under the terms of the

Creative Commons Attribution Non-Commercial License

(http://creativecommons.org/licenses/by-nc-nd/4.0/)

\begin{abstract}
Background. Gastrointestinal stromal tumors (GISTS) are the most common mesenchymal tumors of the digestive system. The primary location of GISTs is mainly the gastrointestinal system. Clinical symptoms are nonspecific and mainly depend on the location and size of the tumor.

Objectives. The aim of this study was to conduct a clinical and pathological analysis of 18 cases of GIST from the medical records of the Department of Surgery at the $4^{\text {th }}$ Military Teaching Hospital in Wrocław, Poland.

Material and methods. The medical records were of women and men at the age of 36-84 years who were treated in the Surgical Clinic. The medical data that was gathered included clinical records, histopathological results and the type of surgical treatment. The study also encompassed the anatomical location and size of the tumor as well as microscopic examination of the tumor.

Results. In most cases, GISTS were located in the stomach. The most common symptoms were stomachaches and signs of bleeding into the digestive system. Usually, the tumor presented a diameter of $<5 \mathrm{~cm}$ and a low grade of malignancy. Out of 18 patients, 16 were treated with laparoscopic resection, whereas in the remaining 2 cases, multiorgan resections were carried out, because the tumor was locally advanced.

Conclusions. It is essential to distinguish stromal tumors from other mesenchymal tumors, since GISTs are among the cancers that have a high risk of malignant progression. The conditions for successful treatment are a properly established histopathological diagnosis, accompanied by immunohistochemical tests for CD117, and a combination of antibodies for a differential diagnosis of other mesenchymal tumors.
\end{abstract}

Key words: gastrointestinal stromal tumor, CD117, tumorectomy, jejunal gastrointestinal stromal tumor, stomach gastrointestinal stromal tumor 


\section{Introduction}

Gastrointestinal stromal tumors (GISTs) are the most common mesenchymal cancers of the gastrointestinal tract. They derive from the precursors of the pacemaker interstitial cells of Cajal, which are responsible for intestinal peristaltic activity. They are characterized by the overexpression of the tyrosine kinase receptor KIT. ${ }^{1}$ Primary GISTs are largely located along the gastrointestinal tract - over $80 \%$ of them. Most frequently, they are found in the stomach (40-70\%) and small intestine (20-50\%). This type of sarcoma less frequently develops in the retroperitoneal space $(<15 \%)$. GISTs rarely occur in the colon $(\sim 5 \%)$ or esophagus $(<5 \%)$. Approximately $30 \%$ of all gastrointestinal stromal tumors present signs of malignancy with evidence of infiltration and distant metastases, especially liver and peritoneal.

Primarily, GISTs develop within the wall of the gastrointestinal tract, below the mucosal layer. They are not attached to the intestinal mucosa, but as the disease advances, they may lead to infiltration and ulceration of the intestinal mucosa. The clinical symptoms of GISTs are nonspecific and depend on the size and anatomical location of the tumor. The most common presentations include abdominal pain, a palpable mass in the abdomen and gastrointestinal bleeding, which can be chronic or less frequently acute. ${ }^{2-4}$ The most effective method of treatment is a complete resection of the tumor. Gastric GISTs are typically removed along with a part of the gastric wall by wedge resection with a margin of 1-2 cm. Metastases to regional lymph nodes are rare; they appear in $<3 \%$ of patients, so systemic lymph node dissection is not generally required. The resectability rate of GISTs is high and varies from 70 to $80 \% .^{5}$

The aim of this study was to analyze the records of patients treated for stromal tumors in the Department of Surgery at the $4^{\text {th }}$ Military Teaching Hospital in Wrocław (Poland) between 2005 and 2015.

\section{Material and methods}

Clinical data, histopathological results and information about the type of operation were collected from the medical records of 18 patients operated on in the Department of Surgery at the $4^{\text {th }}$ Military Teaching Hospital in Wrocław. Clinical symptoms reported before the surgical treatment, the type of resection (R0, R1 or R2), the anatomical location, and the size of the tumor as well as the results of microscopic examination were analyzed.

The study group included 18 patients (11 men and 7 women) aged 36-84 years. The mean age of the study group was 62 years. In all patients, the histopathological diagnosis was determined after the surgical treatment. In the majority of cases, the GIST was located in the stomach (72\%). In 2 patients, it was found in the mesentery; in the
Table 1. Tumor location

\begin{tabular}{|l|c|c|}
\hline \multicolumn{1}{|c|}{ Organ } & Number of cases & Percentage [\%] \\
\hline Stomach & 13 & 72 \\
\hline Small intestine & 1 & 5.5 \\
\hline Rectum & 1 & 5.5 \\
\hline Mesentery & 2 & 11 \\
\hline Retroperitoneal space & 1 & 5.5 \\
\hline Total & 18 & 100 \\
\hline
\end{tabular}

Table 2. Tumor size

\begin{tabular}{|l|c|c|}
\hline \multicolumn{1}{|c|}{ Tumor size $[\mathrm{cm}]$} & Number of cases & Percentage [\%] \\
\hline$<5$ & 12 & 66.7 \\
\hline $5-10$ & 4 & 22.3 \\
\hline $11-20$ & 1 & 5.5 \\
\hline 20 & 1 & 5.5 \\
\hline Total & 18 & 100 \\
\hline
\end{tabular}

remaining single cases, it was located in the small intestine, rectum or retroperitoneal space (Table 1).

The most frequently reported symptoms were abdominal pain and signs of intestinal bleeding, such as anemia and tarry stools. One patient with a tumor in the mesentery presented with episodes of obstruction of the gastrointestinal tract. One woman sought medical advice because of a palpable abdominal tumor. Eight patients were qualified for surgical treatment on the basis of endoscopy suggesting a stomach tumor; however, the biopsy results indicated only inflammatory changes. Other patients were qualified for surgery based on the results of computed tomography imagery of the abdominal cavity. In the majority of cases (66.7\%), the diameter of the tumor was $<5 \mathrm{~cm}$ (Table 2).

All procedures were followed in accordance with the ethical standards and with the Helsinki Declaration of 1964 and later versions. Informed consent was obtained from all the patients included in the study.

\section{Results}

A laparotomy was conducted on 16 patients. In all cases of gastric GIST, a local tumor resection along with a part of the stomach wall or a wedge resection with an oncologic margin was performed. A multiorgan resection was done in 2 patients with locally advanced tumors - a tumor diameter of $>10 \mathrm{~cm}$ and infiltration of the adjacent organs (Table 3). Two patients were operated on laparoscopically for gastric GIST. In the $1^{\text {st }}$ case, a $3 \mathrm{~cm}$ pedunculated endophytic tumor of the fundus was excised; in the $2^{\text {nd }}$ case, a $3.5 \mathrm{~cm}$ exophytic tumor of the anterior was removed.

In the majority of cases (12 patients, $67 \%$ ), the diameter of the tumor was $\leq 5 \mathrm{~cm}$ and they were classified as low to very low risk. Two cases of GIST with a tumor diameter $>10 \mathrm{~cm}$ were classified as high risk. The mitotic index 
Table 3. Type of surgical operation

\begin{tabular}{|c|c|c|}
\hline Type of surgery & Number of operations & Percentage [\%] \\
\hline Tumor resection with a margin including the stomach wall & 11 & 68.75 \\
\hline Segmental resection of the small intestine & 2 & 12.5 \\
\hline Anterior resection of the rectum & 1 & 6.25 \\
\hline $\begin{array}{l}\text { Multiorgan resection } \\
\text { 1. Tumor resection with a margin including the stomach wall, splenectomy, segmental } \\
\text { resection of the transverse colon } \\
\text { 2. Resection of the gastric tumor, segmental resection of the transverse colon }\end{array}$ & 2 & 12.5 \\
\hline Total & 16 & 100 \\
\hline
\end{tabular}

Table 4. The degree of tumor malignancy

\begin{tabular}{|l|c|c|c|c|}
\hline \multicolumn{1}{|c|}{ Risk classification } & Tumor size $[\mathrm{cm}]$ & Mitotic index & Number of cases & Percentage [\%] \\
\hline Very low & $<2$ & $<5 / 50$ & 3 & 16.7 \\
\hline Low & $2-5$ & $<5 / 50$ & 9 & 50 \\
\hline \multirow{2}{*}{ Intermediate } & $<5$ & $6-10 / 50$ & 0 & 22.2 \\
& $5-10$ & $<5 / 50$ & 4 & 11.1 \\
High & $>5$ & $>5 / 50$ & 0 & 100 \\
\hline
\end{tabular}

Table 5. Residual tumor distribution

\begin{tabular}{|l|c|c|}
\hline Presence of residual tumor & Number of cases & Percentage [\%] \\
\hline R0 & 13 & 72 \\
\hline R1 & 5 & 28 \\
\hline R2 & 0 & 0 \\
\hline
\end{tabular}

in all 18 cases remained below 5 . The results of histopathological examination with risk assessment, mitotic index, and tumor size are presented in Table 4.

The final result of microscopic examination confirmed a complete $\mathrm{R} 0$ resection in 13 patients. Tumors located in the mesentery and in the retroperitoneal space were removed with surgical margins showing microscopic evidence of tumor cells (R1 resection). In the 2 cases of gastric GIST with a diameter of $>10 \mathrm{~cm}$, tumor rupture occurred during the procedure, but they were classified as $\mathrm{R} 1$ resections. All tumors were removed without any macroscopic residual tumor (Table 5).

In all 18 patients, the follow-up period lasted from 6 to 60 months. The postoperative period was uneventful in 17 cases. One case of postoperative death occurred in an 84-year-old man who presented symptoms of heart failure. During the follow-up, all patients were recurrencefree. One patient was lost for follow-up. Four patients qualified for adjuvant therapy with imatinib.

\section{Discussion}

Stromal gastrointestinal tumors are rare and challenging for clinicians because of their nonspecific symptoms and an oligosymptomatic clinical course. They are often discovered incidentally during an evaluation for other reasons. A definite histopathological diagnosis is obtained postoperatively due to the subserosal, intramural or submucosal growth of such tumors. In this study, the diagnoses were made postoperatively based on histopathological examination of the excised tissues. Obtaining a representative endoscopic biopsy may be difficult because of the nature of tumor growth. The preferred diagnostic methods are endoscopic ultrasoundguided fine-needle aspiration or Tru-Cut biopsy, especially for small tumors. The usefulness of endoscopic ultrasoundguided fine-needle aspiration was studied by Akahoshi et al. on a group of 53 patients. The overall sensitivity of this method was $82 \%$ (42 out of 53 ). The sensitivity in relation to tumor size was $71 \%$ for lesions up to $2 \mathrm{~cm}, 86 \%$ for lesions of $2-4 \mathrm{~cm}$, and $100 \%$ for lesions over $4 \mathrm{~cm}^{6}$

Discovering the presence of activating mutations in the KIT or platelet-derived growth factor receptor alfa (PDGFRA) genes is crucial for GIST diagnosis. The most important diagnostic tool for GIST is the evaluation of the immunohistochemical expression of $C D 117$, which is found to be positive in $95 \%$ of those tumors. Mutations within the PDGFRA gene are detected in tumors with a mutation-free KIT gene.

The location of the GIST within the gastrointestinal tract is a significant prognostic factor. A gastric location is associated with a better prognosis (only $25 \%$ of such tumors are malignant) than locations in other organs, including the small intestine (50\% of such tumors are malignant), esophagus and colon (the majority of these tumors are malignant). Less frequently, a GIST may appear outside the wall of the gastrointestinal tract, in which case it is found in the mesentery, omentum, retroperitoneum, or pelvic tissues. Typically, however, in those locations, metastases 
of the stromal tumor are found. Histopathological examination requires information about the site of origin of the tumor. In our study group, 3 primary tumors $(16.7 \%)$ were located outside the gastrointestinal tract.

The risk stratification developed on the basis of expert experience from the National Institutes of Health (NIH) distinguishes tumors of very low, low, intermediate, and high risk of recurrence or metastasis. The key elements of this scheme include tumor size and mitotic count assessed in 50/HPF. Additionally, the prognosis takes into account the location of the tumor. Cut-off values for tumor size are 2, 5 and $10 \mathrm{~cm}$, and 5 mitoses per 50 HPF. Tumors larger than $10 \mathrm{~cm}$ with high mitotic activity (over 10/50 HPF) are always of high risk. ${ }^{8}$ In our study group, the majority of tumors (16 patients, 89\%) were classified as not high risk. Only in 1 case (5.5\%) was the tumor classified as high risk.

In the treatment of GISTs, radical surgery is the most effective therapeutic approach. In approx. $75 \%$ of patients, it is possible to perform the first operation with curative intent and remove the lesion with a margin free of tumor (R0 or R1 resection). Increasingly, laparoscopic or endoscopic procedures are being used. Researchers from Korea conducted a retrospective study on 406 patients who were treated surgically for GIST between March 1998 and March 2012. The mean tumor size was $4.9 \mathrm{~cm}$ (ranging from 0.3 to $29 \mathrm{~cm}$ ). All patients underwent radical surgery. Laparoscopic resection was carried out in 156 patients (38.4\%), while the remaining 250 (61.6\%) required open resection. The mean tumor size in the patients treated laparoscopically was significantly smaller than in those who were treated with open surgery $(3.45 \mathrm{~cm}$ vs $5.46 \mathrm{~cm}$; $\mathrm{p}<0.001)$. During the follow-up period, which lasted from 2 to 166 months (median 42.9 months), 11 (2.7\%) cases of recurrence with metastases to the liver $(9$ cases) and peritoneum ( 2 cases) were observed in patients undergoing surgical resection. ${ }^{9}$ Authors from China used endoscopic resection to treat small lesions up to $2 \mathrm{~cm}$ which were located in the stomach and grew into the gastrointestinal tract lumen. This procedure was shorter and associated with less blood loss and a faster recovery of intestinal peristalsis. In 3 out of 50 patients (6\%) who underwent the endoscopic procedure, perforation occurred. One patient was reoperated on because of abdominal infection, while in the remaining patients conservative treatment was effective. ${ }^{10}$ In turn, Honda et al. described a group of 78 patients (32 men, 46 women) with a mean age of 63 years who were treated with laparoscopic surgery for gastric GIST. The mean size of the tumors was $34.7 \pm 12.1 \mathrm{~mm}$. In $92.3 \%$ of patients, tumor resection was performed with a pathologically negative margin, while in $7.7 \%$ of patients, gastrectomy was required. The mean operative time was $147.5 \pm 63.8 \mathrm{~min}$, the mean estimated amount of blood loss was $17.8 \pm 47.9 \mathrm{~mL}$ and the mean length of hospitalization was $9.4 \pm 12.8$ days. Complications such as anastomotic leakage occurred in $2(2.6 \%)$ cases. During the followup period of $45.3 \pm 18.5$ months, 1 patient experienced recurrence in the omentum and 4 other patients died due to other causes. These results convinced the author that laparoscopic resection is an appropriate therapeutic option for lesions up to $5 \mathrm{~cm}$ in diameter. ${ }^{11}$

Stromal tumors constitute approx. $20 \%$ of all tumors of the small intestine. The most common presentation of intestinal GIST is bleeding, while obstruction occurs rarely. Morrison and Hodgdon described 2 patients with a GIST who underwent emergency laparoscopy due to small intestine obstruction. ${ }^{12}$ In a 59-year-old man, the obstruction was caused by an $8 \mathrm{~cm}$ pedunculated tumor, which provoked a rotation of the bowel and its mesentery. In another case of a 24-year-old woman, the obstruction resulted from intussusception of the lesion. Both patients underwent segmental resection of the small intestine affected by the tumor, then a side-to-side anastomosis was created using the Endo GIA ${ }^{\mathrm{TM}}$ stapler. There were no complications in either case. The authors believe that laparoscopic resection for obstructed intestinal tumors is a safe procedure and is associated with less blood loss, shorter hospital stays and less analgesic use in comparison to open surgery. When a small intestinal tumor is suspected in the computed tomography, the presence of GIST shall be considered. During surgery, special care shall be taken to avoid damage to the capsule of the tumor. ${ }^{12}$

In the adjuvant treatment of patients with intermediate and high clinical aggressiveness according to the NIH, tyrosine kinase inhibitors are used because of the high risk of recurrence. ${ }^{13}$ Additionally, a spontaneous rupture of the tumor or rupture during resection increases the risk of peritoneal recurrence and is considered an unfavorable prognostic factor. ${ }^{14}$ The introduction of imatinib has significantly improved prognosis and survival in such patients. Proper histopathological diagnosis, along with an immunohistochemical test for $C D 117$, and a panel of antibodies helpful in differential diagnosis of other mesenchymal cancers are prerequisites to successful therapy. An increase in the incidence of disease progression with longer follow-up times in patients treated with imatinib for disseminated GIST has been observed; thus, attempts at combining imatinib with other invasive methods have been undertaken. ${ }^{15}$ Hakime et al. described a group of $17 \mathrm{pa}-$ tients who underwent radiofrequency ablation of the liver for metastatic GIST. The mean max tumor diameter was $2.5 \pm 1 \mathrm{~cm}$ (range: $0.9-4.5 \mathrm{~cm}$ ). The authors believe that their treatment modality is effective and safe in patients with GIST liver metastases who undergo imatinib treatment, and that the treatment should be applied at the appropriate time for the best clinical response. ${ }^{16}$

\section{Conclusions}

The most common location of GISTs is the stomach (72\%). In the diagnosis of GISTs located in the stomach, endoscopic biopsy results are often negative and indicate the 
inflammatory process of the gastric mucosa. Computed tomography of the abdominal cavity is the best diagnostic test. The majority of GISTs are of very low or low risk of recurrence and metastasis (67\%).

\section{References}

1. Głuszek S, Rylski R, Kot M, et al. GIST: Risk of recurrence and dissemination. Gastroenterol Rev. 2008;3(4):176-184.

2. Prywinski S, Szopiński J, Wierzchowski P, Dąbrowiecki S. Gastrointestinal stromal tumor of small intestine as the cause of massive gastrointestinal hemorrhage: Case report. Pol Surg. 2008;10(2):107-112.

3. Wang YP, Li Y, Song C. Clinicopathological features and prognosis of small gastrointestinal stromal tumors outside the stomach. Oncol Lett. 2015;10(5):2723-2730.

4. Yacob M, Inian S, Sudhaker CB. Gastrointestinal stromal tumors: Review of 150 cases from a single centre. Indian J Surg. 2015;77(2):505-510.

5. Ruka W, Debiec-Rychter M, Rutkowski P, et al. Current diagnostic and therapeutic management of patients with gastrointestinal stromal tumor (GIST). J Oncol. 2007;57(2):181-189.

6. Akahoshi K, Sumida Y, Matsui N, et al. Preoperative diagnosis of gastrointestinal stromal tumor by endoscopic ultrasound-guided fineneedle aspiration. World J Gastroenterol. 2007;13(14):2077-2082.

7. Guzińska-Ustymowicz K, Nasierowska-Guttmejer A. Nowotwory podścieliskowe przewodu pokarmowego. Pol J Pathol. 2013;64(4) (Suppl 2):47-54.
8. Miettinen M, Sobin LH, Lasota J. Gastrointestinal stromal tumors of the stomach: A clinicopathologic, immunohistochemical, and molecular genetic study of 1765 cases with long-term follow-up. Am J Surg Pathol. 2005;29(1):52-68.

9. Kim IH, Kim IH, Kwak SG, Kim SW, Chae HD. Gastrointestinal stromal tumors (GISTs) of the stomach: A multicenter, retrospective study of curatively resected gastric GISTs. Ann Surg Treat Res. 2014;87(6):298-303.

10. Feng F, Liu Z, Zhang $X$, et al. Comparison of endoscopic and open resection for small gastric gastrointenstinal stromal tumor. Transl Oncol. 2015;8(6):504-508.

11. Honda M, Hiki N, Nunobe S, et al. Long-term and surgical outcomes of laparoscopic surgery for gastric gastrointestinal stromal tumors. Surg Endosc. 2014;28(8):2317-2322.

12. Morrison JE, Hodgdon IA. Laparoscopic management of obstructing small bowel GIST tumor. JSLS. 2013;17(4):645-650.

13. Din OS, Woll PJ. Treatment of gastrointestinal stromal tumor: Focus on imatinib mesylate. Ther Clin Risk Manag. 2008;4(1):149-162.

14. Matthews BD, Walsh RM, Kercher KW, et al. Laparoscopic vs open resection of gastric stromal tumors. Surg Endosc. 2002;16(5):803-807.

15. Fu C, Liu N, Deng Q, Tan Y, Ma K, Bie P. Successful treatment of gastrointestinal stromal tumor with multiple liver metastases with radiofrequency ablation and imatinib: A case report. Oncol Lett. 2015;10(2):875-878.

16. Hakime A, Le Cesne A, Deschamps F, et al. A role for adjuvant RFA in managing hepatic metastases from gastrointestinal stromal tumors (GIST) after treatment with targeted systemic therapy using kinase inhibitors. Cardiovasc Intervent Radiol. 2014;37(1):132-139. 